\title{
The Role of Psychobiological and Neuroendocrine Mechanisms in Appetite Regulation and Obesity
}

\author{
Ioanna Paspala ${ }^{1}$, Niki Katsiki ${ }^{2}$, Dorothea Kapoukranidou ${ }^{3}$, Dimitri P Mikhailidis ${ }^{4}$ and Anna \\ Tsiligiroglou-Fachantidou ${ }^{1, *}$
}

${ }^{1}$ Laboratory of Hygiene \& Sports Nutrition, Department of Physical Education and Sport Science, Aristotle University of Thessaloniki, Thessaloniki, Greece

${ }^{2}$ Second Propedeutic Department of Internal Medicine, Medical School, Aristotle University of Thessaloniki, Hippokration Hospital, Thessaloniki, Greece

${ }^{3}$ Department of Physiology and Pharmacology, Medical School, Aristotle University of Thessaloniki, Thessaloniki, Greece

${ }^{4}$ Department of Clinical Biochemistry (Vascular Disease Prevention Clinic), Royal Free Campus, University College London Medical School, University College London (UCL), London, UK

\begin{abstract}
Obesity is a multifactorial disease. Among its causes are physical inactivity and overeating. In addition, other factors may play an important role in the development of overweight/obesity. For example, certain hormones including leptin, insulin and ghrelin, may influence appetite and consequently body weight. Obesity frequently co-exists with metabolic disorders including dyslipidemia, hypertension and insulin resistance, thus constituting the metabolic syndrome which is characterized by increased cardiovascular risk.

Lack of comprehensive knowledge on obesity-related issues makes both prevention and treatment difficult. This review considers the psychobiological and neuroendocrine mechanisms of appetite and food intake. Whether these factors, in terms of obesity prevention and treatment, will prove to be relevant in clinical practice (including reducing the cardiovascular risk associated with obesity) remains to be established.
\end{abstract}

Keywords: Obesity, appetite, psychobiology, neuroendocrine mechanisms, leptin, insulin, ghrelin, cardiovascular risk.

\section{INTRODUCTION}

The digestive system is responsible for the absorption of food and water $[1,2]$. This process occurs along the gastrointestinal tract, starting with mechanical and chemical processes in the mouth [1-3]. Mastication fragments food and involves coordinated rhythmic activity of the neuromuscular system [1,3-5]. Mastication is important for the digestion of all foods and even more for fruits and raw vegetables. Peptide enzymes act primarily on the surfaces of food particles. How fast digestion is achieved depends on the total amount of food exposed to intestinal secretions [4]. A basic characteristic of individuals that masticate food too quickly is that they do not have a sense of satiety, thus leading to enhanced food intake which predisposes them to increased body weight $[1,6,7]$.

\footnotetext{
*Address correspondence to this author at the Laboratory of Hygiene and Sports Nutrition, Department of Physical Education and Sport Science, Aristotle University of Thessaloniki, Thessaloniki, Greece, Thermi 57001; Tel: 00302310992163; Fax: 00302310992163;

Email: fachant@phed.auth.gr
}

\section{THE CONCEPT OF APPETITE}

Along with biological mechanisms, exogenous factors promoting the need for food consumption are important [2]. These factors are primarily 'cognitive' as patterns of behaviour are influenced by family characteristics, lifestyle, religion, social and economic status $[2,8]$. Of particular interest is the separation and clarification of the concept of food intake and eating behaviour. Food intake is a biological phenomenon that aims at maintaining energy balance; it refers to 'what we eat' $[6,8]$. Dietary behaviour refers to "how we eat" and it is an environmental phenomenon affecting the quality of food in dietary preferences and aversions as well as foodinduced "hedonic" effect $[4,6,9]$. There are 'sensors' which alter the 'threshold' between hunger and satiety $[4,5,10]$. These mechanisms seem to be influenced by body weight. The complexity of these processes makes it more difficult to understand the psychobiological interactions $[10,11]$.

\section{PSYCHOBIOLOGICAL MECHANISMS}

Hyperphagia is one of the major causes of obesity $[2,11$, 12]. Several researchers believe that the primary disorder involves food intake mechanisms and metabolic disorders. 
The amount of food intake depends on the number, size and energy content of the meals $[11,13,14]$.

Each meal can be considered as consisting of 3-phases: a) initiation, with hunger being its basic feature [15] b) meal duration, and, c) the end of the meal (satiation).

\section{Initiation of Food Intake}

The biological mechanisms involved in the initiation of each meal include stomach contractions, food taste and energy levels. In particular, although for several years stomach contractions were regarded as the main stimulus, it seems that other mechanisms are involved as well such as psychosocial factors and dieting practices $[2,5,11]$.

Food taste plays a key role on food preference and food choice because of the way that a human can perceive the food but also the sensory affective response to the taste, smell, sight and texture of food $[16,17]$. Food taste for most of the people translates into flavour, smell and oral perception of food texture [17].

There are 'signals' in the circulation that reflect energy reserves [5], one of them being non-esterified fatty acids (NEFAs). Increased concentrations of NEFAs occur in response to lipolysis. So NEFAs are regarded as a biomarker of negative energy balance, if the supply of glucose is insufficient in order to cover energy demands. In obese individuals, NEFAs are constantly increased due to insulin resistance, thus providing a misleading signal of lack of food; as a result obese people eat more than they actually need [18]. Furthermore, there are theories which support the concept that glucose uptake and utilization play a major role in the regulation of hunger, satiety and energy balance. The glucostatic theory maintains that food consumption is activated because of a decrease in blood glucose [19-22]. The lipostatic theory specifies that body fat is the answer to regulate the feeding behaviour $[22,23]$. The aminostatic theory proposes that amino acids in the blood have a significant role in defining satiety [22]. The thermostatic theory claims that temperature that develops in specific sensors in the body, such as central thermoreceptors, could act as a food intake sensor for total energy balance [24]. The hepatostatic theory concentrated on the metabolic activity of the liver [25]. The ischymetric hypothesis suggests that the process of feeding can be regulated by our metabolic rate. When the body is in the process of food absorption, the metabolic rate is faster than in fasting $[26,27]$. It may well be that all these factors play a role with their contributions differing in individuals.

\section{Meal Duration}

Meal duration depends on both endogenous and exogenous mechanisms. Endogenous factors, including a variety of stimuli deriving from the mouth, pharynx, esophagus and the stomach, may cause temporal extension of the meal [2830]. After the food enters the intestine, absorption, an important function of the small intestine, begins.

The exogenous factors that may influence meal duration are food appearance, smell and taste as well as environmental conditions. Satiation occurs when the inhibitory mechanisms dominate over stimulants. Interestingly, the hedonistic effect of food consumption may prolong feeding.
The mesolimbic dopamine pathway may be responsible for this action; tasty foods may release dopamine into the nucleus accumbens [28-31].

\section{End of Meal}

The digestion process initiates in the stomach, where pepsinogen is converted to pepsin by hydrochloric acid, and proceeds to the intestine via the pyloric sphincter. The nervous system and various digestive system hormones [e.g. glucagon and cholecystokinin (CCK)] can control the process which leads to the end of meal. The brain is "informed" about the quantity of food consumption and its nutrient content via sensory stimuli. The gastrointestinal system is equipped with specialised chemo- and mechano-receptors that monitor physiological activity and transfer information to the brain mainly via the vagus nerve $[1,28]$. Among the factors that influence this process during the meal are amino acid levels in the circulation (amino acids are derived from both protein catabolism and their intestinal absorption). According to the aminostatic hypothesis, amino acids act as peripheral signals to the brain in order to maintain the longterm balance between energy intake and energy expenditure as well as body fat mass over days or weeks [24, 32]. In this context, increased muscle catabolism and elevation of amino acids levels leads to feeding, whereas postprandial uptake of amino acids from the plasma into the muscles results in the cessation of feeding and a period of satiety [24, 33].

The absorption rates of amino acids are highly dependent on their protein source. Several amino acids derive from the catabolism of soy protein and milk; however specific milk proteins such as beta-lactoglobulin and casein have different digestibility [24, 33-35]. The classification of whey proteins as "fast proteins" and of caseins as "slow proteins" is consistent with their reported effect on food intake in humans. Whey has been found to reduce food intake at $90 \mathrm{~min}$, whereas casein exerts a stronger effect later (at $150 \mathrm{~min}$ ) $[33,36]$. Furthermore, there is considerable evidence that the effect of whey proteins on satiety and food intake is mediated via the release of certain satiety hormones such as CCK, glucagon like peptide-1 (GLP-1), gastric inhibitory peptide (GIP), peptide YY and ghrelin. Indeed, more than 20 different regulatory peptide hormones are released in the gastrointestinal system and many of them are involved in the regulation of food intake [36, 37]. Furthermore, peripheral opioid and CCK-A receptors can be activated by casein ingestion; blocking these receptors with antagonists reduces their effect on food intake [36-39].

\section{Dietary Choices}

Dietary preference is defined as an option when all kinds of food are available. Practically all types of food are never available at one time, therefore we choose the food we like best or the food that is easier to have at that time. Appetite is characterized by the preference of a particular food over another whose consumption may bring pleasure and taste.

Dietary choices are determined by both biological (genetic, hereditary factors) and environmental factors. Scientific data indicate that appetite or distaste for certain kinds of food is incorporated in our genetic code. We are born with unknown predispositions for sweet or bitter tastes, sour or 
salty tastes $[3,4,7,9,16,40]$. Other factors responsible for dietary choices involve congenital conditions; a plurality of environmental factors determines our dietary preferences including imitation, social and emotional effects, physiological needs, industrial communication policies (i.e. advertising) and seeking new dinning experiences $[4,10,40]$. In obese people the situation is slightly different because the amount of food intake may be increased following its beneficial effect on emotional status (i.e. stress reduction and improvement of depressing feelings) [7, 41, 42]. Interestingly, there is a tendency towards the consumption of foods rich in carbohydrates whenever obese individuals are emotionally distressed [11, 41, 43]. It should also be noted that exogenous factors such as food taste, smell and hedonic effect may have a greater influence on obese people than endogenous factors such as hunger, energy needs and satiation $[3,4,11,41]$.

\section{NEUROENDOCRINE MECHANISMS}

Apart from the psychobiological factors, there is also a 'brain phase' in the food intake process. Experimental data have indicated the presence of several peptides with their receptors in the hypothalamus and other parts of the CNS that may affect the quantity and quality of food intake $[7,15,44,45]$. These peptides act as sensors that transfer signals from the periphery and stimulate or inhibit appetite and food intake accordingly in order to maintain energy homeostasis; not only they regulate the amount of each meal but also long-term energy reserves (i.e. the amount of fat tissue) $[42,46]$. The main hormones involved in this process are insulin and leptin [45, 47].

It should be noted that abdominal fat is the one related to increased cardiovascular (CVD) risk in both genders, as reported in several meta-analyses [48-50]. Consequently, central obesity is included in all definitions of the metabolic syndrome [51-55] and should always be taken into consideration when assessing CVD risk. Furthermore, epicardial fat has been recently associated with coronary artery disease prevalence and severity $[56,57]$. There is also data that correlate epicardial fat thickness with leptin and ghrelin concentrations [58].

\section{Leptin, Insulin and Obesity}

Leptin, one of the most important adipose-tissue derived hormones, plays a major role in the regulation of energy intake and energy expenditure in terms of appetite and metabolism control [59,60]. Leptin is a 167 amino acid protein primarily produced in white adipose tissue. Circulating leptin levels are directly proportional to the total amount of fat in the body. Leptin acts on specific hypothalamic receptors and inhibits appetite by counteracting the effects of the orexigenic neuropeptide Y (NPY) [47,61-63]. Furthermore, leptin enhances the synthesis of alpha menalocyte stimulating hormone $(\alpha-\mathrm{MSH})$, an appetite suppressant [64]. The absence of leptin or its receptor leads to uncontrolled food intake, resulting in obesity [65]. Insulin, a hormone composed of 51 amino acids, is produced by the islets of Langerhans in the pancreas; it can regulate carbohydrate and fat metabolism in the body via glucose utilization in the periphery (e.g. liver and muscles) and inhibition of glucagon release [64]. In the absence of insulin, glucose uptake from peripheral tissues is inhibited; thus hyperglycemia occurs, leading to diabetes, and fat becomes the energy source of the organism via gluconeogenesis [65]. Similarly, in cases of insulin resistance, both obesity and diabetes may arise.

Leptin and insulin were shown to proportionally increase the quantity of body fat after eating [64]. Furthermore, these hormones are able to influence meal duration, metabolic activity and energy intake for a prolonged period of time through interactions with the CNS [44, 45,59]. Certain characteristics of leptin and insulin secretion and action explain why they are regarded as regulators of food intake and energy homeostasis $[47,66-68]$. For example, their levels in the circulation are proportional to adipose tissue mass, they penetrate the blood-brain barrier into the CNS at rates that depend on their plasma concentrations and specific receptors for leptin and insulin have been identified in neurons that control metabolic activity $[64,66,69]$.

Furthermore, their administration directly into the CNS was reported to inhibit food intake in animal models [64,69]. Interestingly, both hyperinsulinemia and insulin resistance exist in obese individuals, probably as a balancing mechanism to inhibit further increases in body weight $[59,62,70]$. Leptin effects on food intake mechanisms seem to be stronger than those of insulin. It has been shown that the absence of leptin in the human body can cause severe obesity, even though insulin levels are high [65]. The interactions between leptin and insulin are complicated while their effects on the endocrine system differ [71-73]. Leptin acts as a negative signal for the brain and suppresses food consumption. On the other hand, insulin promotes glucose uptake from peripheral tissues in a rate proportional to serum leptin levels. Insulin secretion is adjusted in response to acute metabolic changes; insulin levels increase during meals or when glucose is elevated for another reason and decrease during stress and exercise [64, 65,73]. Leptin is secreted from adipocytes in an amount proportional to the metabolic action of fat cells; thus plasma leptin levels are a reliable marker of body fat $[47,74]$. Low leptin levels indicate depleted fat stores and inhibit functions that require adequate energy stores (e.g. reproduction) $[47,64,74]$. Plasma insulin levels have a direct link to body weight and body adiposity; they also reflect acute changes in energy homeostasis [64, 74]. Of note, insulin secretion reflects the amount of visceral white adipose tissue, whereas leptin secretion reflects total fat mass and especially subcutaneous fat mass $[64,75]$. Of note, in obesity, small quantities of food consumption may cause greater reductions in insulin and leptin levels compared with the expected in terms of the increased adipose tissue mass [64]. In response to body fat increase, leptin and insulin levels are also increased [64]. Through the bloodstream, these 2 hormones reach the hypothalamus and activate specific "catabolic" neuroendocrine circuits, which inhibit food intake and increase metabolic activity [ 47, 59, 63]. On the other hand, in cases of body fat reduction (e.g. during dietary weight loss), insulin and leptin levels are also decreased. This process results in a reverse effect of the aforementioned mechanisms, i.e. "anabolic" circuits are activated that increase food intake and meal duration, and reduce metabolic activity $[59,63]$. The "catabolic" neuroendocrine pathways that are stimulated by increases in body 
fat, leptin and insulin levels, involve activation of anorexigenic neurons and inhibition of orexigenic neurons, particularly those that express NPY. On the other hand, when the "anabolic" circuits are activated by body fat reductions, these mechanisms are completely reversed i.e. orexigenic neurons are now stimulated and anorexigenic neurons are suppresed. By these alterations, the CNS controls appetite and food intake in order to maintain energy homeostasis $[62,67,76,77]$. The neuroendocrine circuits that are involved in the control of food intake, are situated in the hypothalamus $[47,70]$. Leptin and insulin receptors are located throughout the CNS and mainly in the arcuate nucleus (ARC) of the ventral hypothalamus [47,69]. Interestingly, in obese individuals, a persistent eating behaviour (i.e. overeating) remains, although blood leptin levels are elevated [64]. The exact causes of this phenomenon are still unknown. However, 2 potential mechanisms may be involved; firstly, it has been proposed that circulating leptin may not be able to penetrate the blood-brain barrier in adequate amounts and thus cannot perform its action in the hypothalamus. Secondly, it is possible that some orexigenic receptors become resistant to leptin and therefore, they cannot be activated by leptin-dependent mechanisms $[62,67,70,76]$.

\section{Ghrelin and Obesity}

Energy balance is achieved by the synergistic action of both endocrine and neural signals from adipose tissue and the gastrointestinal tract as well as the interactions of these signals with the CNS [78-80]. These mechanisms are complicated and interrelated; none of them work independently. In this context, apart from leptin, insulin and NPY, ghrelin, a gastrointestinal hormone, also plays an important role in appetite control and energy homeostasis $[72,74,78,80]$. Ghrelin was first discovered in a rat stomach [81]. It is produced mainly in the dome of the stomach by a specific type of endocrine cells of the gastric mucosa (H/A neuro-secretory cells). Additionally, ghrelin is produced by the kidney, pituitary, hypothalamus and placenta [78, 81]. Of note, ghrelin secretion is rhythmic following the circadian rhythm [80] with increased hormone levels during the night. Typically, circulating ghrelin concentrations are elevated before eating and decline rapidly, soon after a meal [82].

Ghrelin effects on energy balance were studied in mice and rats [78]. Regional daily administration of ghrelin could cause weight increase due to decreased use of fat as energy source; continuous administration of the hormone, both centrally and peripherally, led to a dose-related increase in food intake and, consequently, in body weight [78]. In growth hormone (GH) deficiency, ghrelin reverses the leptin-dependent inhibition of food intake and mRNA expression of the hypothalamic NPY. Therefore, ghrelin acts as endogenous antagonist of leptin [72, 80, 83]. Ghrelin effects on food intake are thought to be mediated within the CNS. The role of the ARC is well established in food intake control [12]. There are 2 key neuronal populations in the ARC; those promoting feeding and those suppressing appetite. Ghrelin targets the neurons that co-expresses the orexigenic peptides NPY and agouti-related protein (AgRP) [80]. In detail, animal studies have demonstrated an increased mRNA expression of the hypothalamic AgRP and NPY following ghrelin administration [80]. Studies in rats showed that plasma ghrelin concentration was increased by fasting and decreased by re-feeding and administration of oral glucose but not with water intake [78].

Overall, ghrelin is a gastric peptide with orexigenic action promoting fat decomposition, informing the hypothalamus when an increase in calories is needed for energy production.[20]. Ghrelin may also exert beneficial direct cardiovascular effects via regulation of energy homeostasis and increased GH release, as well as control of autonomic nervous system and interaction with cardiovascular cells [84]. In this context, ghrelin was found to increase inducible nitric oxide synthase (iNOS) expression in rat hearts [85]. Furthermore, ghrelin was previously shown to bind to a species of high density lipoprotein (HDL) that is associated with the plasma esterase, paraoxonase, and clusterin; this interaction may alter the biostability and activity of ghrelin through conversion of ghrelin to des-acyl ghrelin as the acylated form of ghrelin is the active one [86]. It is important to consider that HDL has multiple actions in addition to reverse cholesterol transport [87]. This finding suggests a link between ghrelin and lipid profile; of note, obesity is frequently characterized by low HDL-cholesterol levels.

Interestingly, obese individuals with GH deficiency were found to have increased small low density lipoprotein (LDL) and HDL particles (i.e. more atherogenic lipids) compared with obese subjects with normal GH levels and non-obese ones [88]. The clinical importance of LDL subfractions has been discussed in a statement by a European panel on LDL subclasses [89]. Lipid-lowering drugs including statins, fibrates, ezetimibe and niacin, as well as anti-obesity agents (e.g. orlistat) were shown to reduce LDL size [90,91]. Rosuvastatin alone or combined with fenofibrate or $\omega-3$ fatty acids not only raised LDL size but also reduced the cholesterol of HDL particles [92]. Whether GH replacement therapy could beneficially affect lipoproteins, thus reducing CVD risk, remains to be established [93].

Obese individuals have lower ghrelin levels compared with similarly aged people with normal weight [78]. In contrast, individuals who suffer from eating disorders, such as anorexia nervosa, have higher plasma ghrelin concentrations than others with normal or below normal body weight $[82,94]$. These findings highlight the fact that ghrelin acts inversely in relation to calorie intake.

Table 1 summarizes the metabolic effects of leptin and ghrelin, as reported in animal studies.

\section{Leptin, Insulin and Ghrelin Interactions in Response to Dietary Status and Cardiovascular Risk Reducing Drug Treatment}

Leptin, insulin and ghrelin are closely related with regard to the regulation of hunger, satiety and nutritional status. In detail, insulin decreases ghrelin production and increases leptin release $[47,95,96]$ while leptin decreases insulin secretion $[64,75]$. Low levels of insulin lead to increased ghrelin concentrations, thus resulting in hunger and food intake [64]. In addition, stored fatty acids are released from fat cells and leptin production by adipose tissue is decreased as fat cells shrink in size. The reduction in leptin release causes a fall in 
Table1. Leptin and Ghrelin Metabolic Effects as Observed in Animal Studies

\begin{tabular}{|l|c|c|}
\hline & Leptin & Ghrelin \\
\hline \hline Body weight & $\downarrow$ & $\uparrow$ \\
\hline Food intake (appetite) & $\downarrow$ & $\uparrow$ \\
\hline Fat oxidation & $\uparrow$ & $\downarrow$ \\
\hline Adiposity & $\downarrow$ & $\uparrow$ \\
\hline Hunger & $\downarrow$ & $\uparrow$ \\
\hline Satiation (after eating) & $\uparrow$ & $\downarrow$ \\
\hline
\end{tabular}

the metabolic rate and thus fewer calories are consumed [76].

After long-term calorie excess, insulin levels are increased and fatty acids enter fat cells.[64] As a consequence, leptin secretion from adipose tissue is increased. Leptin in turn increases adiponectin production [35]. Adiponectin is an adipocyte-derived peptide that beneficially affects several functions such as glucose regulation, fatty acid catabolism and atherosclerosis [97], as well as the production of new fat cells. It follows that adiponectin plays a role in the development of metabolic diseases such as obesity, non-alcoholic fatty liver disease (NAFLD) and metabolic syndrome [15]. When leptin resistance develops, adiponectin levels are decreased despite the presence of elevated leptin concentrations $[62,98]$. As fewer new fat cells are made, the already existing adipose cells, that are full of fatty acids, produce more and more leptin [64]. Eventually, fatty acids start being stored in the muscles and liver, thus impairing insulin sensitivity [64]. Interestingly, increased insulin levels also inhibit the activity of hormone sensitive lipase (HSL), an important muscle enzyme that is involved in the utilisation of stored fatty acids as energy source [64, 99]. HSL is activated in cases of energy need in response to catecholamines and adrenocorticotropic hormone (ACTH). The inhibition of HSL in the presence of hyperinsulinemia leads to the accumulation of even more fatty acids in muscles [99]. The overall result is the development of a continuous vicious cycle of hyperleptinemia, leptin resistance, hyperinsulinemia and insulin resistance, also leading to the consumption of extra calories even though obesity has already developed $[64,75,99]$.

Obesity frequently co-exists with dyslipidemia, hypertension and insulin resistance, which are metabolic syndrome (MetS) components [100]. MetS is characterized by increased CVD morbidity and death as well as all-cause mortality [101,102] supported by meta-analyses [103-105]. Multifactorial treatment was shown to significantly reduce CVD risk in MetS patients [106-108]. In this context, several drugs (e.g. lipid-lowering, antihypertensive, hypoglycemic and weight-reducing) may also influence the levels of these regulatory peptides (i.e. leptin, insulin, ghrelin and NPY) [109]. For example, insulin treatment was shown to increase leptin and decrease NPY levels in diabetic patients; body weight was also increased in insulin-treated patients [110]. This was probably due to other mechanisms such as the ana- bolic effects of insulin, stimulation of lipogenesis, suppression of hepatic glucose production, reduction of basal metabolic rate and elimination of glycosuria. It is also possible that leptin resistance may be partly responsible for the observed weight increase.

With regard to antiobesity drugs, orlistat (an inhibitor of gastrointestinal lipases) and sibutramine (a selective inhibitor of central neuronal reuptake of serotonin and noradrenaline) were found to reduce leptin and increase adiponectin levels in obese patients; orlistat also raised ghrelin concentrations [109]. Similarly, rimonabant (a selective cannabinoid CB1 receptor antagonist) was reported to decrease leptin [111] and increase adiponectin concentrations [112] in obese patients with dyslipidemia. Of note, orlistat, sibutramine and rimonabant also exerted beneficial metabolic effects on waist circumference, lipids and insulin sensitivity, thus contributing to reduced CVD risk [113-116]. Both rimonabant and sibutramine were withdrawn from the market due to psychiatric and cardiovascular (raised blood pressure) side effects, respectively [117-119]. Orlistat is still available for obesity treatment with certain adverse effects and drug interactions that limit its efficacy [120]. As new weight-reducing drugs that are both effective and safe are needed, several developing agents have been evaluated in Phase II and III trials including Contrave [a combination of naltrexone sustainedrelease (SR) + bupropion SR] [121] Qnexa (combination of phentermine with controlled release topiramate) [122] and lorcaserin (a selective 5-hydroxytryptamine receptor 2c agonist) [123]. Apart from weight loss, these drugs also improved cardiometabolic parameters (e.g. waist circumference, lipids, fasting glucose and insulin sensitivity) [121,123, 124]. Lorcaserin was recently (27 June 2012) approved by the U.S. Food and Drugs Administration (FDA) for obesity treatment in addition to lifestyle changes (i.e. diet and exercise) [125]. The drug should not be used in combination with medicines that treat migraine and depression or other drugs that may increase serotonin release or activate serotonin receptors and should be discontinued if $<5 \%$ of initial body weight is lost within 3 months of treatment [125]. Furthermore, it should be used with caution in patients with valve abnormalities since serotonin receptors and metabolism have been implicated to drug-induced valvular heart disease as was the case with methysergide, ergotamine, fenfluramine and dexfenfluramine [126]. Of note, animal studies have reported increased incidences of mammary adenocarcinomas and brain astrocytomas in relation to lorcaserin administration [127]; the company (i.e. Arena Pharmaceuticals) defended the drug stating that lorcaserin concentrations in human brain are significantly lower than the amount used in rats [128].

Qnexa was also approved by the FDA on 17 July 2012 for treating obesity; upon its approval, the drug name was changed to Qsymia to avoid confusion with another drug [129]. The drug should not be used in patients with glaucoma, hyperthyroidism, recent (within the last 6 months) or unstable heart disease and stroke as it increases heart rate; heart rate should be monitored regularly. Furthermore, the drug should be discontinued if the achieved weight reduction is less than $5 \%$ of initial body weight after 3 months of therapy [129]. 
Contrave, although initially rejected by the FDA in the early 2011 due to concerns on CVD risk, has now a second chance as the FDA agreed (in September 2011) to a new cardiovascular outcomes trial design with potential approval in 2014 [130]. The effects of commonly prescribed drugs on adipokines and cardiometabolic factors should be taken into consideration in obesity prevention and treatment. Of note, hypolipidemic drugs, either as monotherapy or in combinations, were reported to reduce the residual vascular risk in obese patients, highlighting their importance in clinical practice [131].

Ghrelin effects on energy balance in humans are not entirely clear, but it was found that ghrelin levels are affected by both acute and chronic variations in nutrition [78]. Of note, the maintenance of weight loss after gastric bypass surgery was shown to be due not only to the reduced stomach volume but also to a reduction in ghrelin levels which were no longer elevated before meals [82]. In general, bariatric surgery represents a promising treatment option in morbidly obese patients, leading to reduced CVD morbidity and mortality; several co-morbidities such as hypertension, dyslipidemia, diabetes and NAFLD are also improved [132].

Apart from the aforementioned hormones, several other peptides are involved in energy homeostasis and food intake control, including resistin, visfatin and retinol binding protein-4 (RBP-4) [133,134]. In this context, these peptides have been associated with MetS and its components such as obesity and insulin resistance, thus contributing to the increased CVD risk that characterizes these metabolic abnormalities [135-138]. Furthermore, visceral and liver fat correlated with visfatin and RBP-4 levels in diabetic patients [139].

\section{CONCLUSIONS}

Obesity is a multifactorial disease, mainly caused by overeating and physical inactivity. Both psychobiological and neuroendocrine mechanisms are involved in the regulation of food intake. In this context, certain hormones including leptin, insulin and ghrelin, as well as the way food is chewed may influence appetite and consequently body weight.

As the prevalence of obesity is rapidly increasing worldwide, there is a need for better understanding of the complex mechanisms that control appetite and food intake. Whether this knowledge, in terms of obesity prevention and treatment, will prove to be relevant in clinical practice remains to be established.

\section{DECLARATION OF INTEREST}

This review was written independently; no company or institution supported it financially. Some of the authors have given talks, attended conferences and participated in trials and advisory boards sponsored by various pharmaceutical companies.

\section{ACKNOWLEDGEMENTS}

None declared.

\section{REFERENCES}

[1] Smit HJ, Kemsley EK, Tapp HS, et al. Does prolonged chewing reduce food intake? Fletcherism revisited. Appetite 2011; 57: 295-8

[2] Booth DA. Physiological regulation through learnt control of appetites by contingencies among signals from external and internal environments. Appetite 2008; 51: 433-41.

[3] Soboḷeva U, Lauriña L, Slaidina A. The masticatory system--an overview. Stomatologija 2005; 7: 77-80.

[4] Bourne MC. Food Texture and Viscosity: Concept and Measurement. $2^{\text {nd }}$ ed. Elsevier Science \& Technology Book. USA: Academic Press 2002

[5] Booth DA. Learnt reduction in the size of a meal. Measurement of the sensory-gastric inhibition of eating from conditioned satiety. Appetite 2009; 52: 745-9

[6] Zheng H, Patterson LM, Berthoud HR. Orexin signaling in the ventral tegmental area is required for high-fat. appetite induced by opioid stimulation of the nucleus accumbens. J Neurosci 2007; 27: 11075-82

[7] Berthoud HR, Morrison C. The brain, appetite, and obesity. Annu Rev Psychol 2008; 59: 55-92

[8] Booth DA. The basics of quantitative judgment. How to rate the strength of appetite for food and its sating. Appetite 2009; 53: 43841

[9] Mennella JA, Pepino MY, Reed DR. Genetic and environmental determinants of bitter perception and sweet preferences. Paediatrics 2005; 115: 216-22

[10] Janssen P, Vanden Berghe V, Verschueren S, et al. Review Article: the role of gastric motility in the control of food intake. Aliment Pharmacol Ther 2011; 33: 880-94

[11] Rogers PJ .Eating habits and appetite control: a psychobiological perspective. Proc Nutr Soc 1999; 58: 59-67

[12] Dhillo WS. Appetite regulation: an overview. Thyroid 2007; 17: 433-45

[13] Monro JA, Mishra S. Glycemic impact as a property of foods is accurately measured by an available carbohydrate method that mimics the glycemic response. J Nutr 2010; 140: 1328-34

[14] Rolls BJ, Roe LS, Meengs JS. Reductions in portion size and energy density of foods are additive and lead to sustained decreases in energy intake. Am J Clin Nutr 2006; 83:11-7

[15] Renaldi O, Pramono B, Sinorita H, et al. Hypoadiponectinemia: A risk factor for metabolic syndrome. Acta Med Indones 2009; 41: 20-4

[16] Rolls ET. Brain mechanisms underlying flavour and appetite. Philos Trans R Soc Lond B Biol Sci 2006; 361: 1123-36

[17] Grabenhorst F, Rolls ET, Bilderbeck A. How cognition modulates affective responses to taste and flavor: top-down influences on the orbitofrontal and pregenual cingulate cortices. Cereb Cortex 2008; 18: $1549-55$

[18] Karpe F, Dickmann JR, Frayn KN. Fatty acids, obesity, and insulin resistance: time for a re-evaluation. Diabetes 2011; 60: 2441-9

[19] Chaput JP, Tremblay A. The glucostatic theory of appetite control and the risk of obesity and diabetes Glucose homeostasis and obesity. Int J Obes 2009; 33: 46-53

[20] Campfield LA, Smith FJ. Blood glucose dynamics and control of meal initiation: a pattern detection and recognition theory. Physiol Rev 2003; 83: 25-58

[21] Kendall CWC, Esfahani A, Sanders LM, et al. The effect of a preload meal containing resistant starch on spontaneous food intake and glucose and insulin responses. J Food Technol 2010; 8: 67-73

[22] Joseph RJ, Alonso-Alonso M, Bond DS, et al. The neurocognitive connection between physical activity and eating behaviour. Obes Rev 2011; 12: 800-12

[23] Sandoval DA, Ryan KK, Kloet AD, et al. Female rats are relatively more sensitive to reduced lipid versus reduced carbohydrate availability. Nutr Diabetes 2012; 2: e27

[24] Halton ThL, Hu FB. The effects of high protein diets on thermogenesis, satiety and weight loss: a critical review. J Am Coll Nutr 2004; 23: 373-85

[25] Henry S. Koopmans. Hepatic control of food intake. Appetite 1984; 5: 127-31

[26] Nicolaidis S. What determines food intake? the ischymetric theory. Physiology 1987; 2: 104-7

[27] Nicolaidis S, Even P. Physiological determinant of hunger, satiation, and satiety. Am J Clin Nutr 1985; 42: 1083-92 
[28] Rogers K. The Digestive System. $1^{\text {st }}$ ed. New York: Britannica Educational Publishing 2011.

[29] National Digestive Diseases Information Clearinghouse. Your Digestive System and How It Works. NIH Publication No. 082681. 2008

[30] Booth DA. Lines, dashed lines and "scale" ex-tricks. Objective measurements of appetite versus subjective tests of intake. Appetite 2009; 53: 434-7

[31] Lutter M, Nestle EJ. Homeostatic and hedonic signals interact in the regulation of food intake. J Nutr. 2009; 139: 629-32

[32] Griffioen-Roose S, Mars M, Siebelink E, et al. Protein status elicits compensatory changes in food intake and food preferences. Am J Clin Nutr 2012; 95: 32-8

[33] Veldhorst M, Smeets MA, Soenen S, et al. Protein-induced satiety: Effects and mechanismsof different proteins. Physiol Behav 2008; 94: $300-7$

[34] Hall WL, Millward DJ, Long SJ, et al. Casein and whey exert different effects on plasma amino acid profiles, gastrointestinal hormone secretion and appetite. Br J Nutr 2003; 89: 239-48

[35] Havel PJ. Section IV: Lipid modulators of islet function. update on adipocytes hormones regulation of energy balance and carbohydrate/lipid metabolism. Diabetes 2004; 53: S143-51

[36] Luhovyy BL, Akhavan T, Anderson GH. Whey proteins in the regulation of food intake and satiety. J Am Coll Nutr 2007; 26: 704S-12S

[37] Murphy KG, Bloom SR. Gut hormones and the regulation of energy homeostasis. Nature 2006; 444: 854-9

[38] Pupovac J, Anderson GH. Dietary peptides induce satiety via cholecystokinin-a and peripheral opioids receptors in rats. J Nutr 2002; 3: 2775-80

[39] Ritter RC. Gastrointestinal mechanisms of satiation for food. Physiol Behav 2004; 81: 249-73

[40] Van der Horst K, Oenema A, Ferreira I, et al. A systematic review of environmental correlates of obesity-related dietary behaviours in youth. Health Educ Res 2006; 22: 203-26

[41] Leigh GE. Emotional influences on food choice: Sensory, physiological and psychological pathways. Physiol Behav 2006; 1: 53-61

[42] Ahima RS, Antwi DA. Brain regulation of appetite and satiety. J Endocrinol Metab Clin North Am. 2008; 37: 811-23

[43] Christensen L. Functional food carbohydrates. Biliaderis CG, Izydorczyk MS. Ed. RC Press 2006; 435-69

[44] EUFIC. Appetite - it's a brain thing. Neural ensemble coding of satiety states. Neuron 2006; 51: 483-94

[45] Dallma MF. Stress-induced obesity and the emotional nervous system. Trends Endocrinol Metab 2009; 21: 159-65

[46] Valassi E, Scacchi M, Cavagnini F. Neuroendocrine control of food intake. Nutr Metab Cardiovasc Dis 2008; 18: 158-68

[47] Williams KW, Scott MM, Elmquist JK. From observation to experimentation: leptin action in the mediobasal hypothalamus. Am J Clin Nutr 2009; 89: 985S-90S

[48] Lee CM, Huxley RR, Wildman RP, Woodward M. Indices of abdominal obesity are better discriminators of cardiovascular risk factors than BMI: a meta-analysis. J Clin Epidemiol 2008; 61: 646-53.

[49] De Koning L, Merchant AT, Pogue J, Anand SS. Waist circumference and waist-to-hip ratio as predictors of cardiovascular events: meta-regression analysis of prospective studies. Eur Heart J 2007; 28: 850-6.

[50] Asia Pacific Cohort Studies Collaboration. Central obesity and risk of cardiovascular disease in the Asia Pacific Region. Asia Pac J Clin Nutr 2006; 15: 287-92.

[51] Alberti KG, Eckel RH, Grundy SM, et al. International Diabetes Federation Task Force on Epidemiology and Prevention; National Heart, Lung, and Blood Institute; American Heart Association; World Heart Federation; International Atherosclerosis Society; International Association for the Study of Obesity. Harmonizing the metabolic syndrome: a joint interim statement of the International Diabetes Federation Task Force on Epidemiology and Prevention; National Heart, Lung, and Blood Institute; American Heart Association; World Heart Federation; International Atherosclerosis Society; and International Association for the Study of Obesity. Circulation 2009; 120: 1640-5.

[52] National Cholesterol Education Program (NCEP) Expert Panel on Detection, Evaluation, and Treatment of High Blood Cholesterol in Adults (Adult Treatment Panel III). Third Report of the National Cholesterol Education Program (NCEP) Expert Panel on Detection, Evaluation, and Treatment of High Blood Cholesterol in Adults
(Adult Treatment Panel III) final report. Circulation 2002; 106: 3143-21.

[53] Alberti KG, Zimmet P, Shaw J. IDF Epidemiology Task Force Consensus Group. The metabolic syndrome: a new worldwide definition. Lancet 2005; 366(9491): 1059-62.

[54] Grundy SM, Cleeman JI, Daniels SR, et al. American Heart Association; National Heart, Lung, and Blood Institute. Diagnosis and management of the metabolic syndrome: an American Heart Association/National Heart, Lung, and Blood Institute Scientific Statement. Circulation 2005; 112: 2735-52.

[55] Alberti KG, Zimmet PZ. Definition, diagnosis and classification of diabetes mellitus and its complications, part 1: diagnosis and classification of diabetes mellitus provisional report of a WHO consultation. Diabet Med 1998; 15: 539-53.

[56] Bachar GN, Dicker D, Kornowski R, Atar E. Epicardial adipose tissue as a predictor of coronary artery disease in asymptomatic subjects. Am J Cardiol 2012; 110: 534-8.

[57] Sacks HS, Fain JN. Human epicardial fat: what is new and what is missing? Clin Exp Pharmacol Physiol 2011; 38: 879-87.

[58] Karayannis G, Giamouzis G, Tziolas N, et al. Association between epicardial fat thickness and weight homeostasis hormones in patients with noncachectic heart failure. Angiology 2012 May 30.[Epub ahead of print]

[59] Brennan AM, Mantzoros CS. Drug Insight: the role of leptin in human physiology and pathophysiology-emerging clinical applications. Nat Clin Pract Endocrinol Metab 2006; 2: 318-27

[60] Sahu A. Leptin signalling in the hypothalamus: emphasis on energy homeostasis and leptin resistance. Front Neuroendocrinol 2003; 24: 225-53

[61] Koch A, Weiskirchen R, Zimmermann HW, et al. Relevance of serum leptin and leptin-receptor concentrations in critically Ill patients. Mediators Inflamm 2010; 2010.pii:473540

[62] Hroussalas G, Kassi E, Dalamaga M, et al. Leptin, soluble leptin receptor, adiponectin and resistin in relation to OGTT in overweight/obese postmenopausal women. Maturitas 2008; 59: 339-49

[63] Kelesidis T, Kelesidis I, Chou S, et al. Narrative review: the role of leptin in human physiology: emerging clinical applications. Ann Intern Med 2010; 152: 93-100

[64] Benoit SC, Clegg DJ, Seeley RJ, et al. Insulin and leptin as adiposity. Signals Recent Prog Horm Res 2004; 59: 267-85

[65] Flakoll PJ, Jensen MD, Cherrington AD. Diabetes mellitus: a fundamental and clinical text. 3rd ed. Philadelphia: Lippincott Williams \& Wilkins 2004

[66] Szanto I, Kahn CR. Selective interaction between leptin and insulin signalling pathways in a hepatic cell line. Proc Natl Acad Sci 2000; 97: $2355-60$

[67] Margetic S, Gazzola C, Pegg1 GG, Hill RA. Leptin: a review of its peripheral actions and interactions. Int J Obes Relat Metab Disord 2002; 6: 1407-33

[68] Enriori PJ, Evans AE, Sinnayah P, et al. Leptin resistance and obesity. Obesity 2006; 14: 254-8

[69] Belgardt BF, Brüning JC. CNS leptin and insulin action in the control of energy homeostasis. Ann NY Acad Sci 2010; 1212: 97113

[70] Wilcox G. Insulin and insulin resistance. Clin Biochem Rev 2005; 26: 19-39

[71] Malendowicz W, Rucinski M, Macchi C, et al. Leptin and leptin receptors in the prostate and seminal vesicles of the adult rat. Int $\mathrm{J}$ Mol Med 2006; 18: 615-8

[72] Ukkola O, Poykko S. Ghrelin, growth and obesity. Ann Med 2002; 34: $102-108$

[73] Strat AL, Kokta ThA, Dodson MV, et al. Early signalling interactions between the insulin and leptin pathways in bovine myogenic cells. Biochim Biophys Acta 2005; 1744: 164-75

[74] Selenscig D, Rossi A, Chicco A, et al. Increased leptin storage with altered leptin secretion from adipocytes of rats with sucroseinduced dyslipidemia and insulin resistance: effect of dietary fish oil. Metabolism 2010; 59: 787-95

[75] Jequier E. Leptin signalling, adiposity, and energy balance. Ann NY Acad Sci 2002; 967: 379-88

[76] Singh A, Wirtz M, Parker N, et al. Leptin-mediated changes in hepatic mitochondrial metabolism, structure, and protein levels. Proc Natl Acad Sci 2009; 106: 13100-5

[77] Kuo LE, Kitlinska JB, Tilan JU, et al. Neuropeptide Y acts directly in the periphery on fat tissue and mediates stress-induced obesity and metabolic syndrome. Nat Med 2007; 13: 803-11 
[78] Tschop M, Smiley DL, Heiman ML. Ghrelin induces adiposity in rodents. Nature 2000; 407: 908-13

[79] Truett GE, Parks EJ. Ghrelin: It's role in energy balance. J Nutr 2005; 135: 1313

[80] Hameed S, Dhillo WS, Bloom SR. Gut hormones and appetite control. Oral Dis 2009; 15: 18-26

[81] Kojima M, Hosoda H, Date Y, et al. Ghrelin is a growth -hormonereleasing acylated peptide from stomach. Nature 1999; 402: 656-60

[82] Cummings DE, Weigle DS, Frayo RS, et al. Plasma ghrelin levels after diet-induced weight loss or gastric bypass surgery. $\mathrm{N}$ Engl $\mathrm{J}$ Med 2002; 346: 1623-30

[83] Johnstone LE, Srisawat R, Kumarnsit E, et al. Hypothalamic expression of NPY mRNA, vasopressin mRNA and CRF mRNA in response to food restriction and central administration of the orexigenic peptide GHRP-6. Stress 2005; 8: 59-67

[84] Kishimoto I, Tokudome T, Hosoda H, Miyazato M, Kangawa K. Ghrelin and cardiovascular diseases. J Cardiol 2012; 59: 8-13.

[85] Sudar E, Dobutovic B, Soskic S, et al. Regulation of inducible nitric oxide synthase activity/expression in rat hearts from ghrelintreated rats. J Physiol Biochem 2011; 67: 195-204

[86] Beaumont NJ, Skinner VO, Tan TM, et al. Ghrelin can bind to a species of high density lipoprotein associated with paraoxonase. J Biol Chem 2003; 278: 8877-80.

[87] Florentin M, Liberopoulos EN, Wierzbicki AS, Mikhailidis DP. Multiple actions of high-density lipoprotein. Curr Opin Cardiol 2008; $23: 370-8$

[88] Makimura H, Feldpausch MN, Stanley TL, Sun N, Grinspoon SK. Reduced growth hormone secretion in obesity is associated with smaller LDL and HDL particle size. Clin Endocrinol (Oxf) 2012; 76: $220-7$

[89] Mikhailidis DP, Elisaf M, Rizzo M, et al. "European panel on low density lipoprotein (LDL) subclasses": a statement on the pathophysiology, atherogenicity and clinical significance of LDL subclasses. Curr Vasc Pharmacol 2011; 9: 533-71.

[90] Florentin M, Tselepis AD, Elisaf MS, Rizos CV, Mikhailidis DP, Liberopoulos EN. Effect of non-statin lipid lowering and antiobesity drugs on LDL subfractions in patients with mixed dyslipidaemia. Curr Vasc Pharmacol 2010; 8: 820-30.

[91] Gazi IF, Tsimihodimos V, Tselepis AD, Elisaf M, Mikhailidis DP. Clinical importance and therapeutic modulation of small dense low-density lipoprotein particles. Expert Opin Biol Ther 2007; 7: 53-72.

[92] Agouridis AP, Kostapanos MS, Tsimihodimos V, et al. Effect of rosuvastatin monotherapy or in combination with fenofibrate or $\omega$ 3 fatty acids on lipoprotein subfraction profile in patients with mixed dyslipidaemia and metabolic syndrome. Int J Clin Pract 2012; 66: 843-53.

[93] Rizzo M, Mikhailidis DP. Lipoprotein alterations and reduced growth hormone secretion: relationships with obesity and cardiovascular risk. Clin Endocrinol (Oxf) 2012; 76: 177-8.

[94] Germain N, Galusca B, Le Roux CW, et al. Constitutional thinness and lean anorexia nervosa display opposite concentrations of peptide YY, glucagon -like peptide 1, ghrelin and leptin. Am J Clin Nutr 2007; 85: $967-71$

[95] Budak E, Sánchez MF, Bellver J, et al. Interactions of the hormones leptin, ghrelin, adiponectin, resistin, and PYY3-36 with the reproductive system. Fertil Steril 2006; 85: 1563-81

[96] Stylianou Ch, Galli-Tsinopoulou A, Farmakiotis D, et al. Ghrelin and leptin levels in obese adolescents. Relationship with body fat and insulin resistance. Hormones 2007; 6: 295-303

[97] Diez JJ, Iglesias P. The role of the novel adipocytes-derived hormone adiponectin in human disease. Eur J Endocrinol 2003; 148: 293-300

[98] Dridi S, Taouis M. Adiponectin and energy homeostasis: consensus and controversy. J Nutr Biochem 2009; 20: 831-9

[99] Kraemer FB, Shen WJ. Hormone-sensitive lipase knockouts. Nutr Metabol 2006; 3:12

[100] Athyros VG, Ganotakis ES, Tziomalos K, et al. Comparison of four definitions of the metabolic syndrome in a Greek (Mediterranean) population. Curr Med Res Opin 2010; 26: 713-9.

[101] Chimonas T, Athyros VG, Ganotakis E, et al. Assessing the treatment effect in metabolic syndrome without perceptible diabetes (attempt) collaborative group. cardiovascular risk factors and estimated 10-year risk of fatal cardiovascular events using various equations in greeks with metabolic syndrome. Angiology 2010; 61: $49-57$.
[102] Hu B, Zhou Y, Liu Y, et al. Impact of metabolic syndrome on clinical outcomes after drug-eluting stent implantation in patients with coronary artery disease. Angiology 2011; 62(6): 440-6.

[103] Mottillo S, Filion KB, Genest J, et al. The metabolic syndrome and cardiovascular risk a systematic review and meta-analysis. J Am Coll Cardiol 2010; 56: 1113-32.

[104] Gami AS, Witt BJ, Howard DE, et al. Metabolic syndrome and risk of incident cardiovascular events and death: a systematic review and meta-analysis of longitudinal studies. J Am Coll Cardiol 2007; 49: 403-14.

[105] Galassi A, Reynolds K, He J. Metabolic syndrome and risk of cardiovascular disease: a meta-analysis. Am J Med 2006; 119: 8129.

[106] Athyros VG, Hatzitolios AI, Karagiannis A, et al; Imperative Collaborative Group. IMproving the implementation of current guidelines for the management of major coronary heart disease risk factors by multifactorial intervention. The imperative renal analysis. Arch Med Sci 2011; 7: 984-92

[107] Athyros VG, Ganotakis E, Kolovou GD, et al; Assessing the treatment effect in metabolic syndrome without perceptible diabetes (Attempt) collaborative. Assessing the treatment effect in metabolic syndrome without perceptible diabetes (attempt): a prospectiverandomized study in middle aged men and women. Curr Vasc Pharmacol 2011; 9: 647-57.

[108] Athyros VG, Karagiannis A, Hatzitolios AI, et al. SAGE-METS collaborative group. Standardized arrangement for a guidelinedriven treatment of the metabolic syndrome: the SAGE-METS study. Curr Med Res Opin 2009; 25: 971-80.

[109] Katsiki N, Mikhailidis DP, Gotzamani-Psarrakou A, et al. Effect of various treatments on leptin, adiponectin, ghrelin and neuropeptide $\mathrm{Y}$ in patients with type 2 diabetes mellitus. Expert Opin Ther Targets 2011; 15: 401-20

[110] Katsiki N, Mikhailidis DP, Gotzamani-Psarrakou A, et al. Effects of improving glycemic control with insulin on leptin, adiponectin, ghrelin and neuropeptide y levels in patients with type 2 diabetes mellitus: a pilot study. Open Cardiovasc Med J 2011; 5: 136-47

[111] Florentin M, Liberopoulos EN, Tellis CC, Derdemezis CS, Elisaf $\mathrm{M}$, Tselepis A. Effects of rimonabant, as monotherapy and in combination with fenofibrate or ezetimibe, on plasma adipokine levels: a pilot study. Angiology 2010; 61: 365-71.

[112] Després JP, Golay A, Sjöström L, Rimonabant in Obesity-Lipids Study Group. Effects of rimonabant on metabolic risk factors in overweight patients with dyslipidemia. N Engl J Med 2005; 353: 2121-34.

[113] Filippatos TD, Mikhailidis DP. Lipid-lowering drugs acting at the level of the gastrointestinal tract. Curr Pharm Des 2009; 15: 490516.

[114] Filippatos TD, Kiortsis DN, Liberopoulos EN, Georgoula M, Mikhailidis DP, Elisaf MS. Effect of orlistat, micronised fenofibrate and their combination on metabolic parameters in overweight and obese patients with the metabolic syndrome: the Fenorli study. Curr Med Res Opin 2005; 21: 1997-2006

[115] Florentin M, Liberopoulos EN, Filippatos TD, et al. Effect of rimonabant, micronised fenofibrate and their combination on cardiometabolic risk factors in overweight/obese patients: a pilot study. Expert Opin Pharmacother 2008; 9: 2741-50.

[116] Kakafika AI, Mikhailidis DP, Karagiannis A, Athyros VG. The role of endocannabinoid system blockade in the treatment of the metabolic syndrome. J Clin Pharmacol 2007; 47: 642-52.

[117] Le Foll B, Gorelick DA, Goldberg SR. The future of endocannabinod-oriented clinical research after CB1 antagonists. Psychopharmacology (Berl) 2009;205:171-4.

[118] Czernichow S, Batty D. Withdrawal of sibutramine for weight loss: where does this leave clinicians? Obes Facts 2010; 3: 155-6.

[119] Florentin M, Liberopoulos EN, Elisaf MS. Sibutramine-associated adverse effects: a practical guide for its safe use. Obes Rev 2008; 9: 378-87.

[120] Filippatos TD, Derdemezis CS, Gazi IF, Nakou ES, Mikhailidis DP, Elisaf MS. Orlistat-associated adverse effects and drug interactions: a critical review. Drug Saf 2008; 31: 53-65

[121] Katsiki N, Hatzitolios AI, Mikhailidis DP. Naltrexone sustainedrelease (SR) + bupropion SR combination therapy for the treatment of obesity: 'a new kid on the block'? Ann Med 2011; 43: 249-58.

[122] Bays HE, Gadde KM. Phentermine/topiramate for weight reduction and treatment of adverse metabolic consequences in obesity. Drugs Today (Barc). 2011; 47: 903-14 
[123] Bays HE. Lorcaserin: drug profile and illustrative model of the regulatory challenges of weight-loss drug development. Expert Rev Cardiovasc Ther 2011; 9: 265-77

[124] Allison DB, Gadde KM, Garvey WT, et al. Controlled-release phentermine/topiramate in severely obese adults: a randomized controlled trial (EQUIP). Obesity (Silver Spring) 2012; 20: 330-42.

[125] Available at: http://www.fda.gov/NewsEvents/Newsroom/PressAnnouncements/ucm309993.htm

[126] Bhattacharyya S, Schapira AH, Mikhailidis DP, Davar J. Druginduced fibrotic valvular heart disease. Lancet 2009; 374: 577-85.

[127] Heal DJ, Gosden J, Smith SL. What is the prognosis for new centrally-acting antiobesity drugs? Neuropharmacology 2012; 63: 13246.

[128] Available at: http://seekingalpha.com/article/623681-fda-obesitydrug-decisions-on-june-27-and-july-17-will-affect-these-stocks

[129] Available at: http://www.fda.gov/NewsEvents/Newsroom/PressAnnouncements/ucm312468.htm

[130] Available at: http://www.drugs.com/nda/contrave_110920.html

[131] Athyros VG, Tziomalos K, Karagiannis A, Mikhailidis DP. Dyslipidaemia of obesity, metabolic syndrome and type 2 diabetes mellitus: the case for residual risk reduction after statin treatment. Open Cardiovasc Med J 2011; 5: 24-34.

[132] Athyros VG, Tziomalos K, Karagiannis A, Mikhailidis DP. Cardiovascular benefits of bariatric surgery in morbidly obese patients. Obes Rev 2011; 12: 515-24.
[133] Athyros VG, Tziomalos K, Karagiannis A, Anagnostis P, Mikhailidis DP. Should adipokines be considered in the choice of the treatment of obesity-related health problems? Curr Drug Targets 2010; 11: 122-35.

[134] Filippatos TD, Randeva HS, Derdemezis CS, Elisaf MS, Mikhailidis DP. Visfatin/PBEF and atherosclerosis-related diseases. Curr Vasc Pharmacol 2010; 8: 12-28.

[135] Filippatos TD, Derdemezis CS, Gazi IF, et al. Increased plasma visfatin levels in subjects with the metabolic syndrome. Eur J Clin Invest 2008; 38: 71-2.

[136] Malo E, Ukkola O, Jokela M, et al. Resistin is an indicator of the metabolic syndrome according to five different definitions in the Finnish Health 2000 survey. Metab Syndr Relat Disord 2011; 9: 203-210.

[137] Christou GA, Tselepis AD, Kiortsis DN. The metabolic role of retinol binding protein 4: an update. Horm Metab Res 2012; 44: 614.

[138] Chang YH, Chang DM, Lin KC, Shin SJ, Lee YJ. Visfatin in overweight/obesity, type 2 diabetes mellitus, insulin resistance, metabolic syndrome and cardiovascular diseases: a meta-analysis and systemic review. Diabetes Metab Res Rev 2011; 27: 515-27.

[139] Shaker O, El-Shehaby A, Zakaria A, et al. Plasma visfatin and retinol binding protein- 4 levels in patients with type 2 diabetes mellitus and their relationship to adiposity and fatty liver. Clin Biochem 2011; 44: 1457-6.

Received: August 06, 2012

Accepted: September 01, 2012

(C) Paspala et al.; Licensee Bentham Open.

This is an open access article licensed under the terms of the Creative Commons Attribution Non-Commercial License (http://creativecommons.org/licenses/ by-nc/3.0/) which permits unrestricted, non-commercial use, distribution and reproduction in any medium, provided the work is properly cited. 